\title{
Comparison of Decellularized Bubaline Diaphragmatic Scaffold with Synthetic Polygalactin and Polypropylene Composite Mesh for Perineal Hernioplasty in Dogs
}

\author{
Suwarna Agrawal, Apra Shahi", Randhir Singh, Rakhi Vaish, Pankaj Jain, Shobha Jawre, \\ Babita Das and Jyoti Navade \\ ${ }^{1}$ Department of Veterinary Surgery and Radiology, Nanaji Deshmukh Veterinary Science University, Jabalpur, \\ Madhya Pradesh, INDIA \\ ${ }^{2}$ Department of Veterinary Anatomy and Histology, Nanaji Deshmukh Veterinary Science University, Jabalpur, \\ Madhya Pradesh, INDIA \\ "Corresponding author: A Shahi; E-mail: aprashahi12@rediffmail.com
}

Received: 17 Sept., 2019

Revised: 28 March, 2020

Accepted: 31 March, 2020

\section{ABSTRACT}

Present study was planned to compare xenogenic decellularized bubaline diaphragmatic scaffold with synthetic polygalactin and polypropylene composite mesh for repair of perineal hernia in dogs. Twelve dogs suffering with perineal hernia were randomly divided in to two equal groups. In group I perineal hernioplasty was done with Synthetic polygalactin and polypropylene composite mesh while in group II, with decellularized bubaline diaphragmatic scaffold (dBDS). Mean surgical time was 59.17 \pm 14.04 and $57.50 \pm 6.15$ minute in group I and II respectively. Swelling, redness and warmth increased significantly $(\mathrm{p}<0.05)$ on day 3 in both the groups. In group II initially significantly $(p<0.05)$ increased exudation was observed on day 3 which reduced gradually. Degree of pain after surgery was significantly $(\mathrm{P}<0.05)$ decrease on day 3 in both the groups. Neutrophil count was significantly $(\mathrm{p}<0.05)$ increased and correspondingly lymphocyte count significantly $(\mathrm{p}<0.05)$ decreased on day 7 in group I while in group II no significant difference within the group was observed. Colour Doppler ultrasonographic examination revealed no vascularization on 0 day in both the groups. Neovascularization was observed on day 30 in group I and day 14 in group II on Colour Doppler ultrasonographic examination. It was increased on day 90 in both the groups. The complication encountered in the present study includes local seroma, suture dehiscence due to self mutilation, constipation and fistula formation. Decellularized bubaline diaphragmatic scaffold was well accepted by all the animals and showed less complication than synthetic mesh.

Keywords: Decellularized bubaline scaffold, dogs, composite mesh, perineal hernia

Perineal hernia has been described as a failure of the supporting structures of the pelvic outlet resulting in an inability of the pelvic diaphragm to retain the pelvic organs. The exact cause of muscle weakening is still unknown however; some factors such as neurogenic or senile atrophy, myopathies, prostatic hyperplasia, hormonal imbalance and chronic constipation have been described as predisposing factors (Ribeiro, 2010). Perineal hernia occurs commonly in middle age or old intact male dogs and rarely in females. The disease is associated with constipation, obstipation, dyschesia, a soft perineal swelling and occasionally urinary problems. The swelling is usually ventrolateral to anus (Vnuk et al., 2008).

Several techniques for the surgical treatment of perineal hernia have been described, including direct apposition of surrounding tissue with non absorbable sutures, internal obturator muscle transposition, superficial gluteal muscle

How to cite this article: Agrawal, S., Shahi, A., Singh, R., Vaish, R., Jain P., Jawre, S., Das, B. and Navade, J. (2020). Comparison of decellularized bubaline diaphragmatic scaffold with synthetic polygalactin and polypropylene composite mesh for perineal hernioplasty in dogs. J. Anim. Res., 10(2): 205-213. 
transposition, semitendinosus muscle flap, synthetic mesh implants etc (Stoll et al., 2002). There are many complications associated with these techniques including mesh infection, adhesions to underlying viscera, fistula formation, mesh extrusion and foreign body reaction associated with use of synthetic mesh material (Falagas and Kasiakor, 2005).

To overcome these synthetic mesh related complications, biomaterials, derived from animal sources, may be preferred for the surgical repair of the abdominal defects. Biological material are considered superior to synthetic materials for the repair of abdominal wall defects, owing to their ability to minimize adhesion formation, provide a better framework for fibroblast proliferation and neovascularization. Moreover, their multidirectional fibrous structure help in batter suture retention, complete absorption and replacement by host tissue (Clarke et al., 1996). Therefore present research was designed to compare xenogenic decellularized bubaline diaphragmatic scaffold with synthetic polygalactin and polypropylene composite mesh for repair of perineal hernia in dogs.

\section{MATERIALS AND METHODS}

The study was conducted on 12 adult dogs suffering with perineal hernia. The animals were selected irrespective of sex, breed and body weight and randomly divided in to two groups of six animals each. Perineal hernioplasty was done with synthetic polygalactin and polypropylene composite mesh in group I and decellularized bubaline diaphragmatic scaffold in group II.

\section{Preparation of decellularized bubaline diaphragmatic scaffold}

Tendinous portion fresh buffalo diaphragm was collected in phosphate buffer saline (PBS) supplemented with antibiotics i.e. gentamicin@ @ 80 $\mu \mathrm{g} / \mathrm{ml}$, from the local slaughter house and cleaned thoroughly in sterile physiological normal saline. It was decellularized by using $1 \%$ SDS according to method of Jain (2017) (Fig. 1). The decellularization of the prepared diaphragmatic scaffolds were confirmed microscopically using haematoxylin and eosin, nuclear (DAPI) staining (Fig. 2), agarose gel electrophoresis and DNA quantification as performed by Jain (2017).

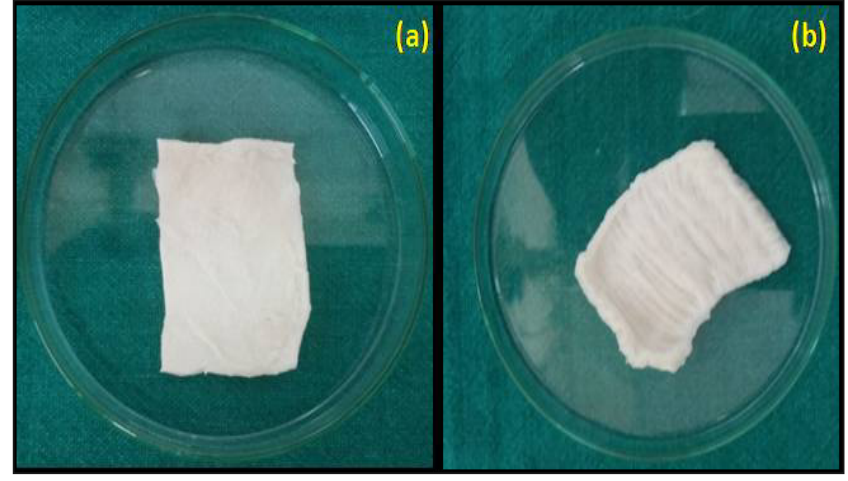

Fig. 1: Fresh frozen bubaline diaphragm (a), decellularized bubaline diaphragm (b)

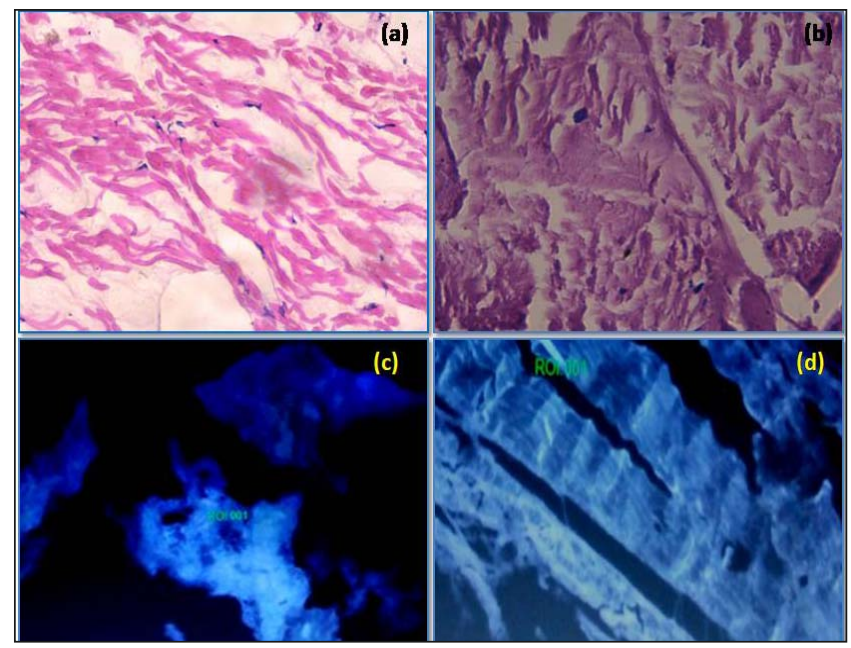

Fig. 2: Section of diaphragmatic tissue (H\&E X400); before decellularization showing nuclei (a), after decellularization without nuclei (b); API staining (400X); before decellularization, nucleus visible (c), after decellularization, no nucleus visible (d)

\section{Anamnesis and Diagnosis}

Complete history of all the cases was recorded including age, clinical signs, soft perineal swelling, duration of perineal hernia and side of hernia. Diagnosis of perineal hernia was done by per rectal examination, radiography, contrast radiography (Fig. 3) and ultrasonographic and Colour Doppler examination. Complete blood count was done to evaluate health status of animal. Sodium phosphate enema was given in all dogs 24 hours before surgery to evacuate rectal content. 

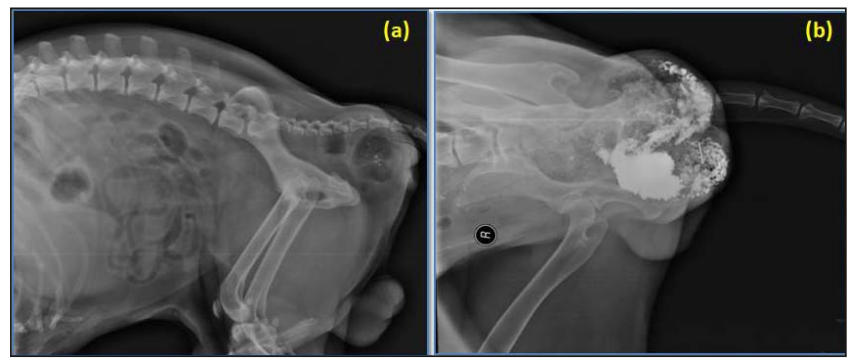

Fig. 3: Survey radiograph of perineal swelling (a), contrast radiograph using barium enema for bilateral perineal swelling (b)

\section{Surgical procedure}

Animal was premedicated with atropine sulphate @ $0.04 \mathrm{mg} / \mathrm{kg}$ b.wt. I/M and xylazine hydrochloride @ 1.5 $\mathrm{mg} / \mathrm{kg}$ b.wt. I/M followed 10 minutes later by ketamine hydrochloride @ 6-8 mg/kg b.wt. I/M as general anaesthetic. Maintenance of the anaesthesia was done by ketamine hydrochloride I/V as per the requirement.

The dogs were restrained in sternal recumbency with the elevated pelvis. Purse-string suture was placed at anal sphincter before surgery. The urethra was catheterized to allow identification of urethra during surgery. Paramedian curvilinear skin incision was given over the hernial sac. Perineal fascia was incised and hernial content identified by blunt dissection, prolapsed organs were repositioned and excess fat was amputated.

Pelvic diaphragmatic defect was repaired with polygalactin and polypropylene synthetic composite mesh in group I and decellularized bubaline diaphragmatic scaffold of appropriate size in group II (Fig. 4 and Fig. 5) by using absorbable suture material polygalactin 910 in horizontal mattress pattern, leaving a 5 to $10 \mathrm{~mm}$ edge on mesh/ scaffold. Three to four sutures was placed from the mesh/ scaffold to the coccygeus muscles and three to four from $\mathrm{mesh} / \mathrm{scaffold}$ to the internal obturator muscles and three to four from mesh/ scaffold to the external obturator muscle. After all suture placements, they were tied, securing the mesh/scaffold to the pelvic diaphragm muscles. Where defect was present dorsally, additional interrupted sutures were placed from the coccygeal muscle to external anal sphincter muscle.

Surgical site was lavaged with sterile solution. Deep and superficial subcutaneous tissue was opposed using polygalactine 910 suture material in simple continuous suture pattern. The skin was opposed using silk in a simple interrupted pattern (Al-Akraa, 2015).

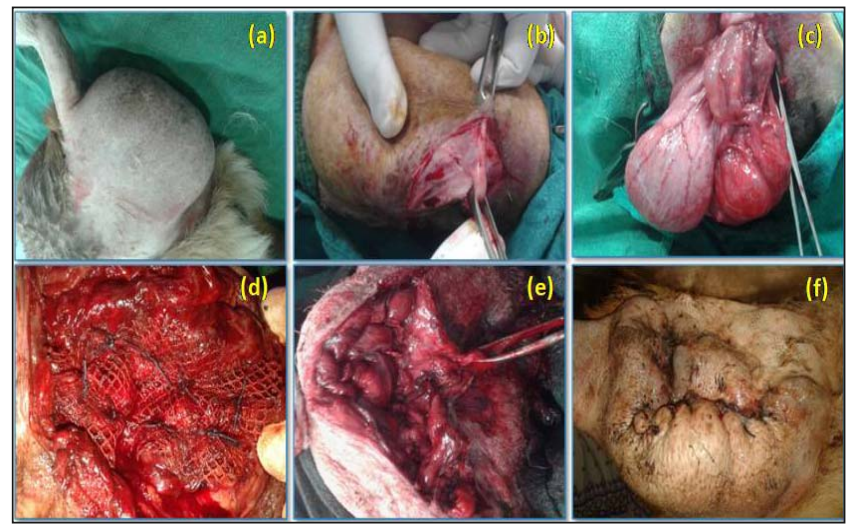

Fig. 4: Repair of hernia by polygalactin-910 and polypropylene composite mesh in group I, perineal swelling (a), curvilinear skin incision (b), hernial contents, bladder and prostate (c), placement of composite mesh (d), suturing of muscle layer over the mesh (e), skin suture (f)

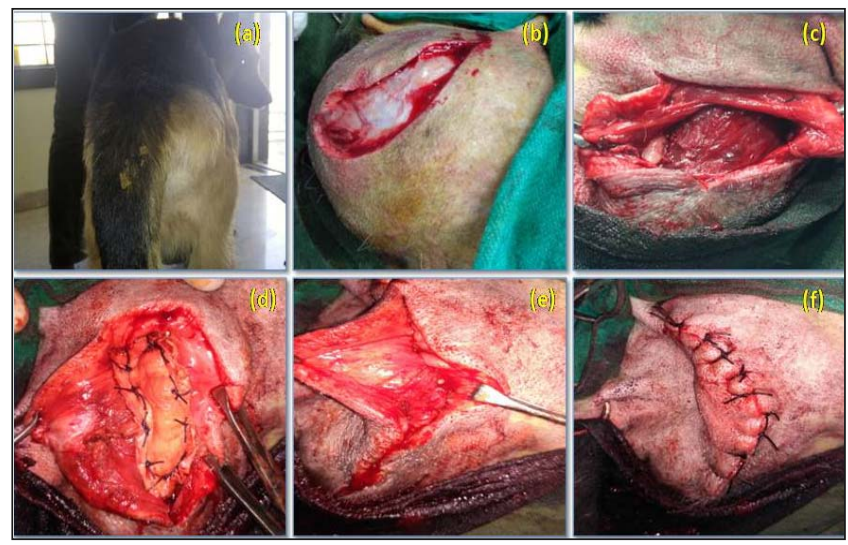

Fig. 5: Repair of hernia by decellularized diaphragmatic scaffold in group II, perineal swelling (a), curvilinear skin incision (b), hernial content rectum (c), placement of decellularized scaffold (d), suturing of muscle layer over the scaffold (e), skin suture (f)

Antibiotic (Ceftriaxone @ $20 \mathrm{mg} / \mathrm{kg}$ body weight) and anti-inflammatory (Meloxicam@0.5 mg/body weight) were given for 7 days and 3 days, respectively. Antiseptic dressing was done with metronidazole povidone iodine solution till removal of sutures. The owner was advised to feed the animal with laxative diets however stool softeners were not added. Skin sutures were removed at $10-12^{\text {th }}$ postoperative day. 


\section{Clinical observation}

Each dog was assessed for rectal temperature and inflammation at surgical site at day 0 followed by on day 3 , 7,14 postoperatively. The degree of swelling and redness at the site of repair was graded as per Stoll et al. (2002) with slight modification. No redness or swelling (1), mild redness or swelling (2), moderate redness or swelling (3) and extreme redness or swelling (4).

The degree of exudation at the site of repair was graded as per Singh et al. (2008). No exudation (1), slight exudates (2), moderate exudates (3) and extreme exudates (4).

Warmth at the site of repair was compared with normal area touching with palm and it was graded as per Kumar et al. (2002). Normally warm (1), mildly warm (2), moderately warm (3) and hot (4).

The degree of pain was assessed by gentle pressing of operative site and was graded as per Singh et al.(2008) with slight modifications. No pain on manipulation (1), Mild pain on manipulation (2), moderate pain on manipulation (3) and severe pain on manipulation (4).

\section{Haematological examination}

Five milliliters blood was collected aseptically from the saphenous / cephalic vein in EDTA containing vaccutainer on 0,7 and 14 days post operatively. Total leukocyte count (TLC) and Differential leucocyte count (\%) were estimated.

\section{Colour Doppler Ultrasonographic examination}

Colour Doppler ultrasonographic examination was done immediately after operation and on 14, 30, 60 and 90 days post operatively to check post operative adhesion, displacement of scaffold and to evaluate microcirculation in the scaffold.

\section{Post operative complications}

Post operative complications were recorded in two stages. In stage I, early complications were recorded, which occurred within 15 days and in stage II, late complications were recorded which occurred within 3 months.

\section{STATISTICAL ANALYSIS}

The data were analyzed using one-way ANOVA as described by Snedecor and Cochran (1994) to compare the mean value within and at corresponding interval among groups.

\section{RESULTS AND DISCUSSION}

\section{Anamnesis}

All the animals were intact male dogs between 6-10 years of age. Out of 12, four animals showed bilateral perineal hernia.

\section{Clinical observation}

Mean values of Rectal temperature are depicted in table 1 while mean values of degree of swelling, redness, exudation, warmth and pain are depicted in table 2 . In most of the dogs hernial content was rectum however urinary bladder, prostate and intestinal loops were also observed.

\section{Rectal temperature}

The rectal temperature was within the normal range for all dogs at each time interval (Table 1). It was observed that the mean values did not differ significantly $(p>0.05)$ within and between the groups at different time interval. It may be due to absence of infection or any other systemic reaction affecting the physiological status of animal. Similar finding were recorded by Gahlod et al. (2010) and Rajhans (2013).

Table 1: Mean value of rectal temperature $\left({ }^{\circ} \mathrm{F}\right)$ in dogs of both the groups

\begin{tabular}{lll}
\hline Interval (Days) & Group I & Group II \\
\hline 0 & $101.00 \pm 0.36$ & $100.60 \pm 0.19$ \\
3 & $101.40 \pm 0.36$ & $101.03 \pm 0.11$ \\
7 & $100.70 \pm 0.46$ & $100.48 \pm 0.18$ \\
14 & $100.42 \pm 0.54$ & $100.43 \pm 0.18$ \\
\hline
\end{tabular}

\section{Degree of swelling, redness and exudation}

Swelling and redness was not seen on day 0 in both the groups which increased significantly $(\mathrm{p}<0.05)$ at day 3 up to $2.33 \pm 0.42$ and $2.17 \pm 0.17$ in group I and II, respectively. 
Table 2: Mean values of degree of swelling and redness, exudation, warmth and pain in dogs of both the groups

\begin{tabular}{|c|c|c|c|c|c|c|c|c|}
\hline \multirow{2}{*}{$\begin{array}{l}\text { Interval } \\
\text { (Days) }\end{array}$} & \multicolumn{2}{|c|}{ Degree of swelling and redness } & \multicolumn{2}{|c|}{ Degree of exudation } & \multicolumn{2}{|c|}{ Degree of warmth } & \multicolumn{2}{|c|}{ Degree of pain } \\
\hline & G I & G II & G I & G II & G I & GII & G I & G II \\
\hline 0 & $1.00^{\mathrm{a}} \pm 0.00$ & $1.00^{\mathrm{a}} \pm 0.00$ & $1.00 \pm 0.00$ & $1.00^{\mathrm{a}} \pm 0.00$ & $1.00^{\mathrm{a}} \pm 0.00$ & $1.00^{\mathrm{a}} \pm 0.00$ & $3.67^{\mathrm{a}} \pm 0.21$ & $3.33^{\mathrm{a}} \pm 0.21$ \\
\hline 3 & $2.33^{b} \pm 0.42$ & $2.17^{b} \pm 0.17$ & $1.50 \pm 0.22$ & $1.83^{\mathrm{b}} \pm 0.31$ & $1.83^{\mathrm{b}} \pm 0.17$ & $1.50^{\mathrm{b}} \pm 0.22$ & $1.50^{\mathrm{b}} \pm 0.22$ & $2.17^{\mathrm{b}} \pm 0.31$ \\
\hline 7 & $1.33^{\mathrm{a}} \pm 0.21$ & $1.17^{\mathrm{a}} \pm 0.17$ & $1.33 \pm 0.21$ & $1.33^{\mathrm{ab}_{ \pm}} \pm .21$ & $1.00^{\mathrm{a}} \pm 0.00$ & $1.00^{\mathrm{a}} \pm 0.00$ & $1.17^{\mathrm{b}} \pm 0.17$ & $1.33^{\mathrm{c}} \pm 0.21$ \\
\hline 14 & $1.00^{\mathrm{a}} \pm 0.00$ & $1.00^{\mathrm{a}} \pm 0.00$ & $1.00 \pm 0.00$ & $1.00^{\mathrm{a}} \pm 0.00$ & $1.00^{\mathrm{a}} \pm 0.00$ & $1.00^{\mathrm{a}} \pm 0.00$ & $1.00^{\mathrm{b}} \pm 0.00$ & $1.00^{c} \pm 0.00$ \\
\hline
\end{tabular}

Mean value within same group with different superscript varied significantly $(\mathrm{p}<0.05)$.

Table 3: Mean values of Total leukocyte count (x 103/ $\mu$ l) and Differential leukocyte count (\%) in dogs of both the groups

\begin{tabular}{|c|c|c|c|c|c|c|c|c|c|c|}
\hline \multirow{3}{*}{$\begin{array}{l}\text { Interval } \\
\text { (Days) }\end{array}$} & \multirow{2}{*}{\multicolumn{2}{|c|}{$\begin{array}{c}\text { Total leukocyte count (X } \\
\left.10^{3} / \mu \mathrm{l}\right)\end{array}$}} & \multicolumn{8}{|c|}{ Differential leukocyte count (\%) } \\
\hline & & & \multicolumn{2}{|l|}{ Neutrophil } & \multicolumn{2}{|c|}{ Lymphocyte } & \multicolumn{2}{|l|}{ Monocyte } & \multicolumn{2}{|l|}{ Eosinophil } \\
\hline & G I & G II & G I & G II & G I & G II & G I & G II & G I & G II \\
\hline 0 & $10.30^{\mathrm{a}} \pm 0.96$ & $13.24 \pm 1.61$ & $70.50^{\mathrm{a}} \pm 1.88$ & $71.17 \pm 4.46$ & $25.33^{\mathrm{a}} \pm 1.45$ & $25.83 \pm 4.00$ & $2.67 \pm 0.33$ & $2.33 \pm 0.49$ & $1.00 \pm 0.15$ & $0.67 \pm 0.33$ \\
\hline 7 & $18.82^{\mathrm{b}} \pm 1.57$ & $18.43 \pm 1.67$ & $77.83^{b} \pm 0.91$ & $75.00 \pm 1.93$ & $19.50^{\mathrm{b}} \pm 1.09$ & $21.50 \pm 1.89$ & $2.00 \pm 0.37$ & $2.67 \pm 0.33$ & $0.67 \pm 0.33$ & $0.83 \pm 0.40$ \\
\hline 14 & $12.12^{\mathrm{a}} \pm 1.10$ & $13.92 \pm 1.59$ & $71.17^{\mathrm{a}} \pm 1.30$ & $69.33 \pm 2.39$ & $25.67^{\mathrm{a}} \pm 1.12$ & $26.83 \pm 2.23$ & $2.33 \pm 0.67$ & $2.50 \pm 0.76$ & $0.83 \pm 0.30$ & $1.00 \pm 0.26$ \\
\hline
\end{tabular}

Mean value within same group with different superscript varied significantly $(\mathrm{p}<0.05)$.

Subsequently, it reduced on day $7,1.33 \pm 0.21$ and $1.17 \pm 0.17$ in group I and II, respectively and later on returned to no swelling in both the groups. Excessive swelling was not observed in any animal of both the groups. Similarly exudation was not seen on day 0 in both the groups which increased significantly $(\mathrm{p}<0.05)$ at day 3 up to $1.83 \pm 0.31$ in group II also non- significant $(\mathrm{p}>0.05)$ increase was observed at day 3 in group I. Later on it followed the similar pattern of degree of swelling in both the groups. Mean values of degree of swelling, redness and exudation did not differ significantly between the groups.

Mild to moderate swelling and redness at the surgical site was attributed to vasodilation and increased blood supply leading to pouring of protein rich fluid out the blood vessels containing inflammatory cells. Development of new blood vessels into the area of tissue trauma also contribute to increased exudation. These finding are in accordance with the reports of Vegad (1995). Kumar et al. (2015) reported mild inflammatory edema during first week of surgery and complete resolution between 10-12 days post-operatively.

\section{Degree of warmth}

Warmth was not recorded on day 0 in both the groups which increased significantly $(\mathrm{p}<0.05)$ at day 3 up to $1.83 \pm 0.17$ and $1.50 \pm 0.22$ in group I and II, respectively and returned to normal level on day 7 in both groups. Degree of warmth did not differ significantly between the groups. Mild warmth was observed at the site of reconstruction at day 3 was attributed to the increased vascularity at the operative site. These findings are in accordance with the study of Silver et al.(1982).

\section{Degree of pain}

Pain prior to surgery was moderate to mild observed during manipulation and per rectal examination. Pain on 0 day $3.67 \pm 0.21$ and $3.33 \pm 0.21$ in group I and II respectively, which decreased significantly $(\mathrm{p}<0.05)$ at day $3,1.50 \pm 0.22$ and $2.17 \pm 0.31$ and return to normal level in group I and II respectively. Degree of pain did not differ significantly between the groups.

This is in accordance with the study of Stoll et al. (2002). Injury to tissues causes a number of changes in the nociceptive system. The injured nociceptors become highly sensitized to stimuli. Inflammatory mediators released during and after surgery also sensitize the peripheral nociceptors to further stimuli (Treede et al., 1992). This may be reason of pain in the present study. 


\section{Haematological parameters}

Mean values of Total leukocyte count $\left(\times 10^{3} / \mu 1\right)$ and Differential leukocyte count $(\%)$ in dogs of both the groups are given in table 3 .

\section{Total leukocyte count}

Total leukocyte count increased significantly $(\mathrm{p}<0.05)$ at day 7 in group I $(18.28 \pm 1.57)$. In group II also nonsignificant $(p>0.05)$ increase was observed at day 7 which return to normal level at day 14 in both the groups. Total leukocyte count was increase on day 7 associated with inflammation. This is in accordance with the study of Singh et al. (2008).

\section{Differential leukocyte count}

Neutrophil count increased significantly $(p<0.05)$ at day 7 in group I (77.83 \pm 0.91$)$ and in group II also non significant increase was observed at day 7 which was returned to normal level at day 14 in both the groups.

Lymphocyte count decreased significantly $(p<0.05)$ in group I (19.50 \pm 1.09$)$ and in group II also non-significant decrease was observed at day 7 which was returned to normal level at day 14 in both the groups. The neutrophilia that occurred briefly suggested that surgical trauma rather than the implant provoked the response. This is in accordance with the study of Gangwar et al. (2006) and Kumar (2009). The changes in eosinophil, and monocyte count were non-significant $(p>0.05)$ at different time interval in all the groups. This is in accordance with the study of Gangwar et al. (2006) and Singh et al. (2008).

\section{Colour Doppler ultrasonographic examination}

Ultrasonographic examination showed no post operative adhesions and displacement of scaffold. Colour Doppler ultrasonographic examination to evaluate microcirculation in the Scar/scaffold revealed no vascularization at day 0 in both the groups (Table 4). On day 14 in group I vascularization was not observed in any case. Whereas in group II in $66.67 \%$ cases mild neovascularization $(4.5 \mathrm{~cm} / \mathrm{s})$ was observed. On day $30,50 \%$ cases showed mild and in Group II, 83.33\% cases showed moderate neovascularization ( $5 \mathrm{~cm} / \mathrm{s}$ ) (Fig. 6). On day 60, in group I, $83.33 \%$ and in group II, $100 \%$ cases showed moderate neovascularization. On day 90 in group I, 100\% vascularity was observed where as in group II, vascularity increased in all cases.

Table 4: Per cent of vascularity/neovascularization in dogs of both groups

\begin{tabular}{lllll}
\hline & \multicolumn{1}{c}{ Group I } & & \multicolumn{1}{c}{ Group II } \\
\cline { 2 - 5 } Days & $\begin{array}{l}\text { No. of } \\
\text { dogs }\end{array}$ & $\begin{array}{l}\text { Vascularity/ } \\
\text { Neovascularization } \\
\text { Per cent }\end{array}$ & $\begin{array}{l}\text { No. of } \\
\text { dogs }\end{array}$ & $\begin{array}{l}\text { Vascularity/ } \\
\text { Neovascularization } \\
\text { Per cent }\end{array}$ \\
\hline 0 & 0 & 0.00 & 0 & 0.00 \\
14 & 0 & 0.00 & 4 & 66.67 \\
30 & 3 & 50.00 & 5 & 83.33 \\
60 & 5 & 83.33 & 6 & 100.00 \\
90 & 6 & 100.00 & 6 & 100.00 \\
\hline
\end{tabular}

Dhaliwal et al. (2017) reported that post-operative ultrasonographic examination showed the stability and correct positioning of mesh and verified the local inflammatory edema and its resolution. Colour Doppler studies revealed neovascularization and healing at the site of hernia.

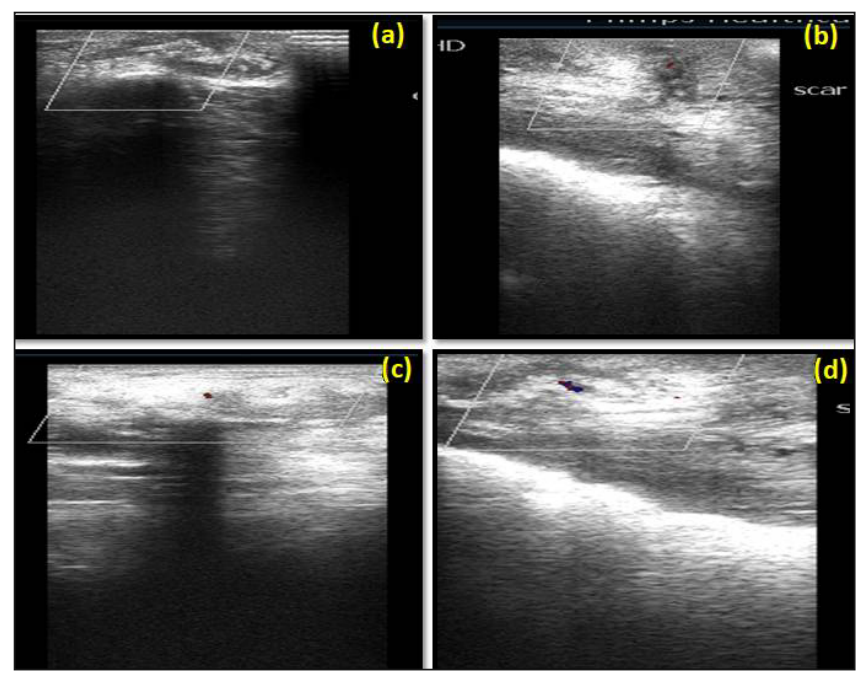

Fig. 6: Colour Doppler ultrasonogram at day 14 showing, no vascularization in group I (a), mild vascularization in group II (b); at day 30 showing mild vascularization in group I (c), moderate vascularization in group II (d)

Complete clinical healing was observed in all the cases of group I and group II at day 90 (Fig. 7) and no difference was observed at the site of incision in both the groups. 

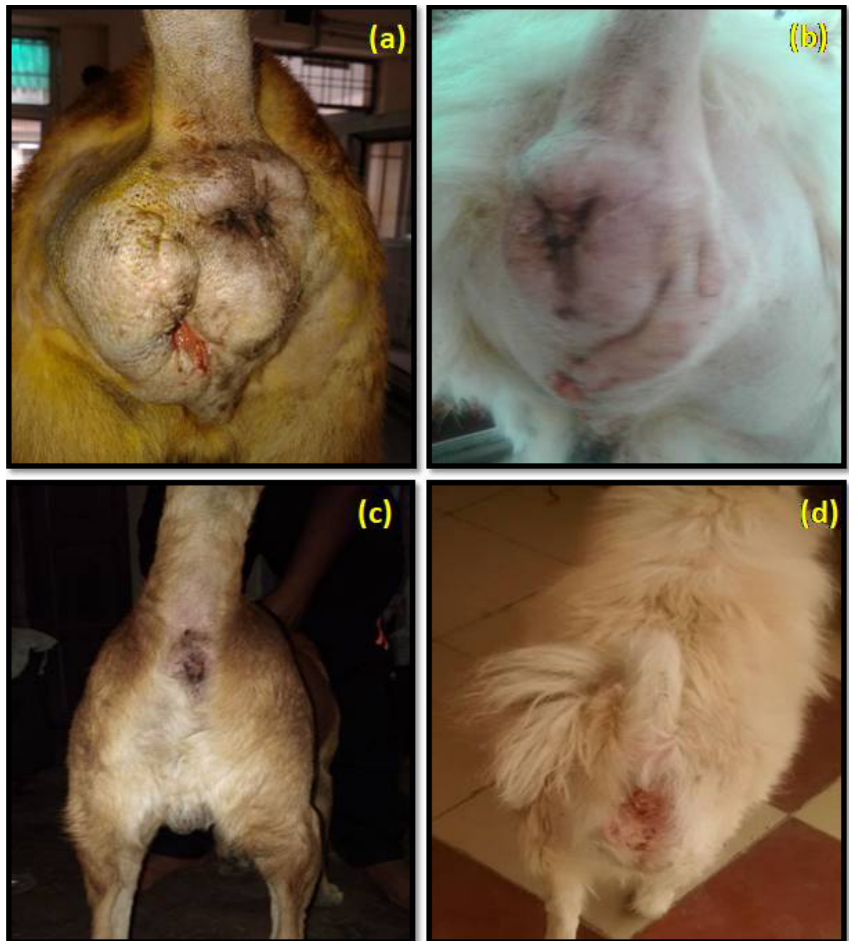

Fig. 7: Post operative observation at day 14 in group I (a), in group II (b) and at day 90 in group I (c), in group II (d)

\section{Post operative complication}

\section{Early complication}

Local seroma, suture dehiscence, constipation and fistula were recorded (Table 5) as early complications in polygalactin and polypropylene composite mesh implanted cases (Fig. 8). Bowman et al. (1998) reported seroma formation where as Elce et al. (2005) reported tearing of the internal abdominal oblique muscle and incisional swelling and drainage and some degree of seroma or haematoma formation at the surgical site after surgery. The greater surface area of multifilament synthetic mesh has been shown to promote the persistence of bacteria in the implant bed (Klinge et al., 2002). Suture dehiscence in the present study may occur due to continuous irritation and inflammation induced by mesh at the site of repair as also state by Kassam et al. (2014).

In the present study tenesmus was observed in the dog suffering with bilateral hernia which may be due to postoperative inflammation, pain, severe rectal dilatation or tension when performing bilateral repair as reported by Pelaez (2014).

Table 5: Per cent of different complication in both groups

\begin{tabular}{lllll}
\hline Complication & Group I & Per cent & Group II & Per cent \\
\hline Local seroma & 1 & 16.67 & 1 & 16.67 \\
Suture dehiscence & 1 & 16.67 & 0 & \\
Self mutilation & 0 & & 1 & 16.67 \\
Constipation/ tenesmus & 1 & 16.67 & 0 & \\
Fistula formation & 1 & 16.67 & 0 & \\
Recurrence up to 3 & NIL & & NIL & \\
months & & & & \\
\hline
\end{tabular}

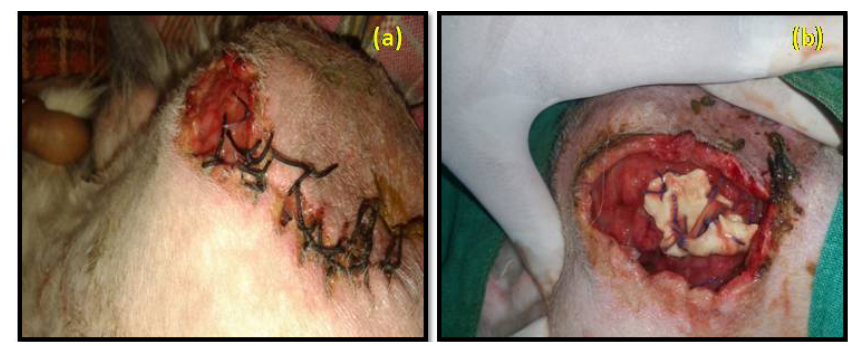

Fig. 8: Post operative complications; suture dehiscence in group I (a) and self mutilation in group II (b)

Seroma formation and self-mutilation were recorded in group II which may be due to inflammation and irritation. Histopathological examination of self mutilated piece of decellularized diaphragmatic scaffold on day 7 postoperative showed cellular infiltration (Fig. 9). The formation of seroma is the body response to surgery. An inflammatory response occurs which leads to flooding the area with a clear fluid. In some cases, the fluid forms a pocket, which leads to the formation of a seroma (Biggers, 2016).

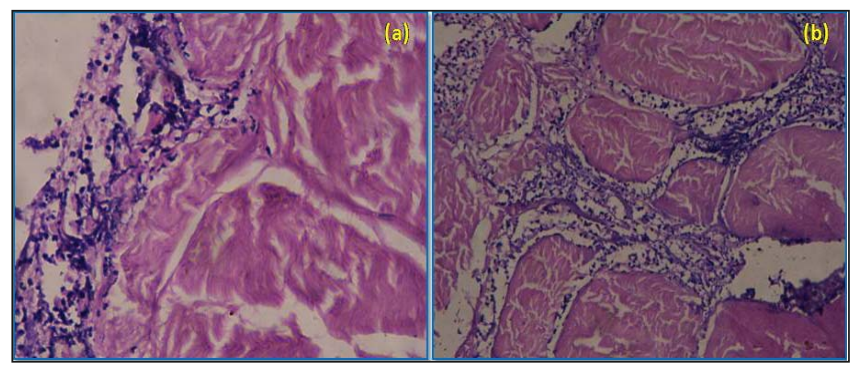

Fig. 9: Microscopic section of decellularized scaffold on day 7 postoperative showing cellular infiltration (a) H\&E X400 and H\&E X100 (b) 


\section{Late complications}

Recurrence of hernia was not observed in both the groups up to 3 months period. This showed that both the materials were equally strong for hernioplasty. This is accordance with the study of Stoll et al. (2002).

\section{CONCLUSION}

With these findings it can be concluded that both synthetic polygalactin and polypropylene composite mesh and decellularized bubaline diaphragmatic scaffold can be used for repair of perineal hernia in dogs without recurrence. However, scaffold resulted in lesser degree of complications. Definitely, the xenogenic nature of scaffold did not disqualify its use in different species of animals as no rejection was observed.

\section{ACKNOWLEDGEMENTS}

Author is thankful to Dean, College of Veterinary Science and Animal Husbandry and Animal Biotechnology centre, Adhartal, Jabalpur (M.P.) for providing required facilities for successful completion of the research work.

\section{REFERENCES}

Al-Akraa, A.M. 2015. Standard Herniorrhaphy, polypropylene mesh and tension band for repair of perineal hernia in dogs. Int. J. Adv. Res., 10(3): 174-180.

Biggers. 2016. Should i worry about seroma. Online https:// www.medicalnewstoday.com/articles/312876

Bowman, K.L., Birchard, S.J. and Bright, R.M. 1998. Complications associated with the implantation of polypropylene mesh in dogs and cats: a retrospective study of 21 cases (1984-1996). J, Am, Anim, Hosp, Assoc., 34(3): 225-233.

Clarke, K.M., Lantz, G.C., Salisbury, K., Badylak, S.F., Hiles, M.C. and Voytik, S.L. 1996. Intestinal submucosa and polypropylene mesh for abdominal wall repair in Dogs. $J$. Surg. Res., 60: 107-114.

Dhaliwal, A.S., Singh, T., Verma, P., Mohindroo, J., Saini, N.S., Raghunath, and Singh, N. 2017. Evaluation of suture herniorrhaphy and polypropylene mesh hernioplasty techniques for perineal hernia in dogs. Indian J. Vet. Surg., 30(1): 14-17.

Elce, Y.A., Kraus, B.M. and Orsini, J.A. 2005. Mesh hernioplasty for repair of incisional hernias of the ventral body wall in large horses. Equine Vet. Edu., 17(5): 252-256.
Falagas, M.E. and Kasiakou, S. K. 2005. Mesh-related infections after hernia repair surgery. Clin. Micro. Infec., 11(1): 3-8.

Gahlod, T.R., Dhakate, M.S., Upadhye, S.A.S. and Bawaskar, S.S. 2010. Management of femoral fracture with the use of horn peg in canine. Vet. World, 3(1): 37.

Gangwar, A.K., Sharma, A.K., Kumar, N., Kumar, N., Maiti, S.K., Gupta, O.P. Goswani, T.K. and Singh, R. 2006. Acellular dermal graft for repair of abdominal wall defect in rabbits. J. Sou. Afric. Vet. Asso., 77(2): 7985.

Jain, P. 2017. Study on xenogenic biological scaffold for repair of muscular defect in rabbit. Ph.D. thesis (Surgery and Radiology), Nanaji Deshmukh Veterinary Science University, Jabalpur.

Kassam, M.M., Elkammet, M.H., Korittum, A.S. and AbdelWahed, A. 2014. Use of polypropylene mesh for herniplasty in calves. Alex. J. Vet. Sci., 40(1): 112-117.

Klinge, U., Junge, K., Spellerberg, B., Piroth, C., Klosterhalfen, B. and Schumpelick, V. 2002. Do multifilament alloplastic meshes increase the infection rate? Analysis of the polymeric surface, the bacteria adherence, and the in vivo consequences in a rat model. J. Biomed. Materials Res., 63(6): 765-771.

Kumar, H. 2009. Evaluation of Fish Air Bladder as a Graft for Cystoplasty in Dogs. Ph.D. thesis (Surgery and Radiology), Birsa Agricultural University, Kanke, Ranchi, Jharkhand.

Kumar, N., Sharma, A.K., Singh, G.R. and Gupta, O.P. 2002. Carbon fiber and plasma preserved tendon allograft for the gape repair of flexor tendon in bovine: Clinical, radiological and angiographical observation. J. Vet. Med. Series A, 49: 161-168.

Kumar, V., Gangwar, A.K., Kumar, N. and Singh, H. 2015. Use of bubaline acellular diagphragm matrix for umbilical hernioplasty in pig. Vet. Arhiv, 85(1): 49- 58.

Pelaez. 2014. Perineal Hernia Repair. Online www.ivis.org

Rajhans, M. 2013. Stabilization of sphinicters of long bone fracture in dogs. M.V.Sc. And A.H. thesis Veterinary Surgery and Radiology). Nanaji Deshmukh Veterinary Science University, Jabalpur, Madhaya Pradesh.

Ribeiro, J.C. 2010. Hernia perineal em Cases: avaliacao e resolucao cirurgica: artigo de revisao. Rev. Luso. Cien. E Med. Vet., 3: 26-35.

Silver, J., Lorenz, S. E., Wahlsten, D. and Coughlin, J. 1982. Axonal guidance during development of the great cerebral commissures: descriptive and experimental studies, in vivo, on the role of preformed glial pathways. J. Comp. Neu., 210(1): 10-29.

Singh, J., Kumar, N., Sharma, A.K., Maiti, S.K., Goswami, T.K. and Sharma, A.K. 2008. Acellular biomaterials of porcine origin for the reconstruction of abdominal wall defects in rabbits. Trends Biomater Artif Organs, 22(1): 34-44. 
Snedecor, C.W. and Cochran, W.G. 1994. Statistical method, $8^{\text {th }}$ Edn., Oxford and IBH publishing Co., Bombay, pp. 593.

Stoll, M.R., Cook, J.L., Pole, E.R., Carson, W.L. and Kreeger, J.M. 2002. The use of pocine intestinal submucosa as a biomaterial for perineal herniorrhphy in dog. Vet. Surg., 31: 379- 390 .

Treede, R.D., Meyer, R.A. and Raja, S.M. 1992. Peripheral and central mechanisms of cutaneous hyperalgesia. Prog. Neuro., 38: $397-421$.
Vegad, J.L. 1995. Texbook of veterinary General Pathology. $1^{\text {st }}$ Edn., Vikas House Pvt. Ltd. Publishing Co., Jangpura, New Dehli, $441 \mathrm{p}$.

Vnuk, D., Lipar, M., Maticic, D., Smolec, O., Pacin, M. and Barkic, A. 2008. Comparison of standard perineal herniorrhaphy and transposition of the internal obturator muscle for perineal hernia repair in dog. Veterinarski Arh., 78: 197 - 207. 
